Supporting Information for Environmental Science and Technology paper (es050891g) entitled:

\title{
Emissions of Chromium, Copper, Arsenic, and PCDDs/Fs from Open Burning of CCA Treated Wood
}

Shirley J. Wasson+, William P. Linak*t, Brian K. Gullett+,

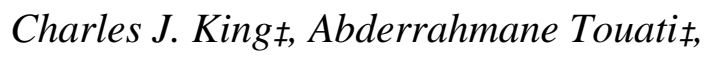

Frank E. Hugginss, Yuanzhi Chens, Naresh Shahs, Gerald P. Huffmans

National Risk Management Research Laboratory, E305-01, Office of Research and

Development, U.S. Environmental Protection Agency, Research Triangle Park, NC 27711, USA

ARCADIS G\&M, Inc., Durham, NC 27709 USA

Consortium for Fossil Fuel Science, University of Kentucky, Lexington, KY 40506, USA

*Corresponding author - tel: 919-541-5792; fax: 919-541-0554; e-mail: linak.bill@epa.gov

†U.S. Environmental Protection Agency

‡ARCADIS G\&M, Inc.

$\S$ University of Kentucky 


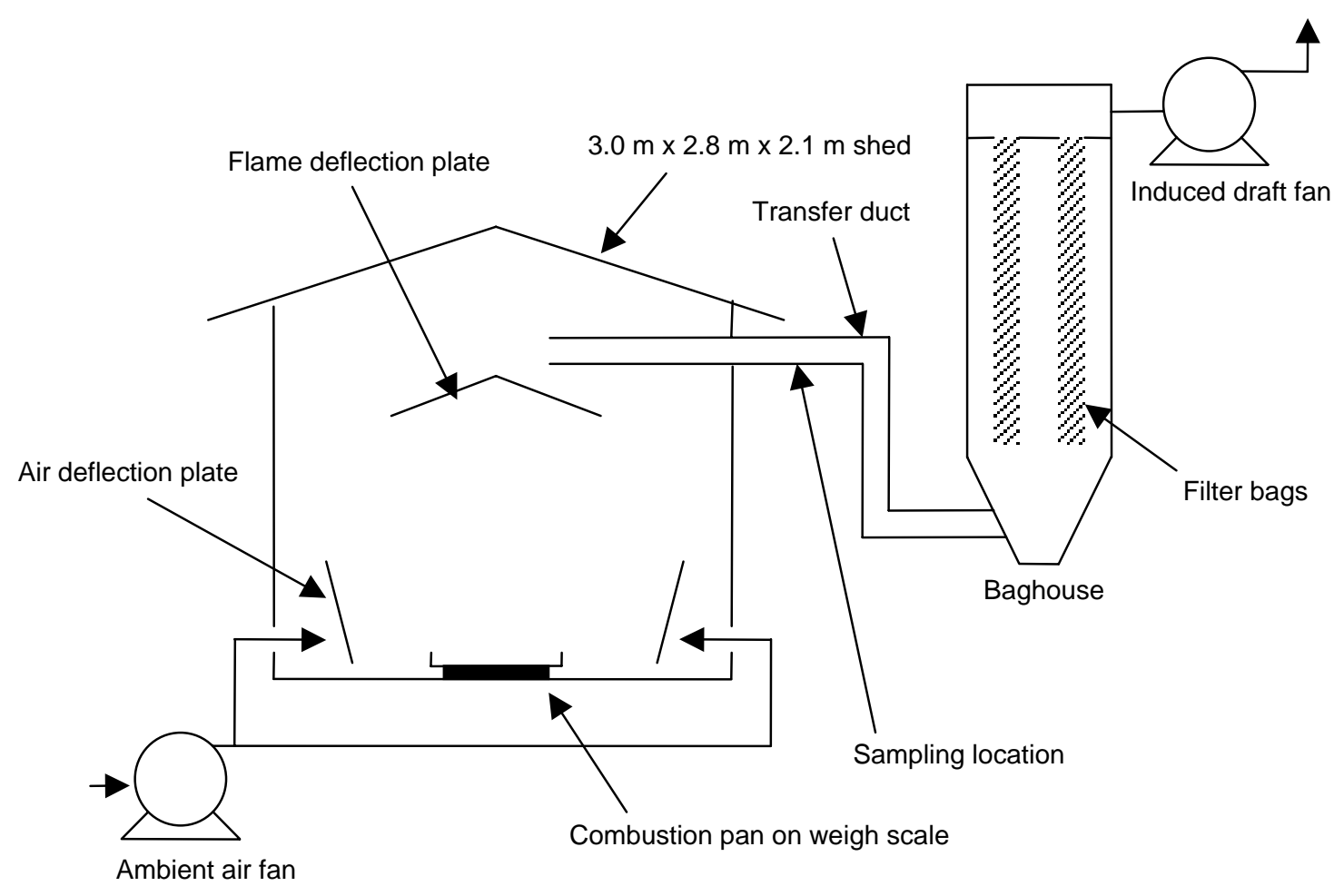

Figure S1: EPA open burn test facility. 


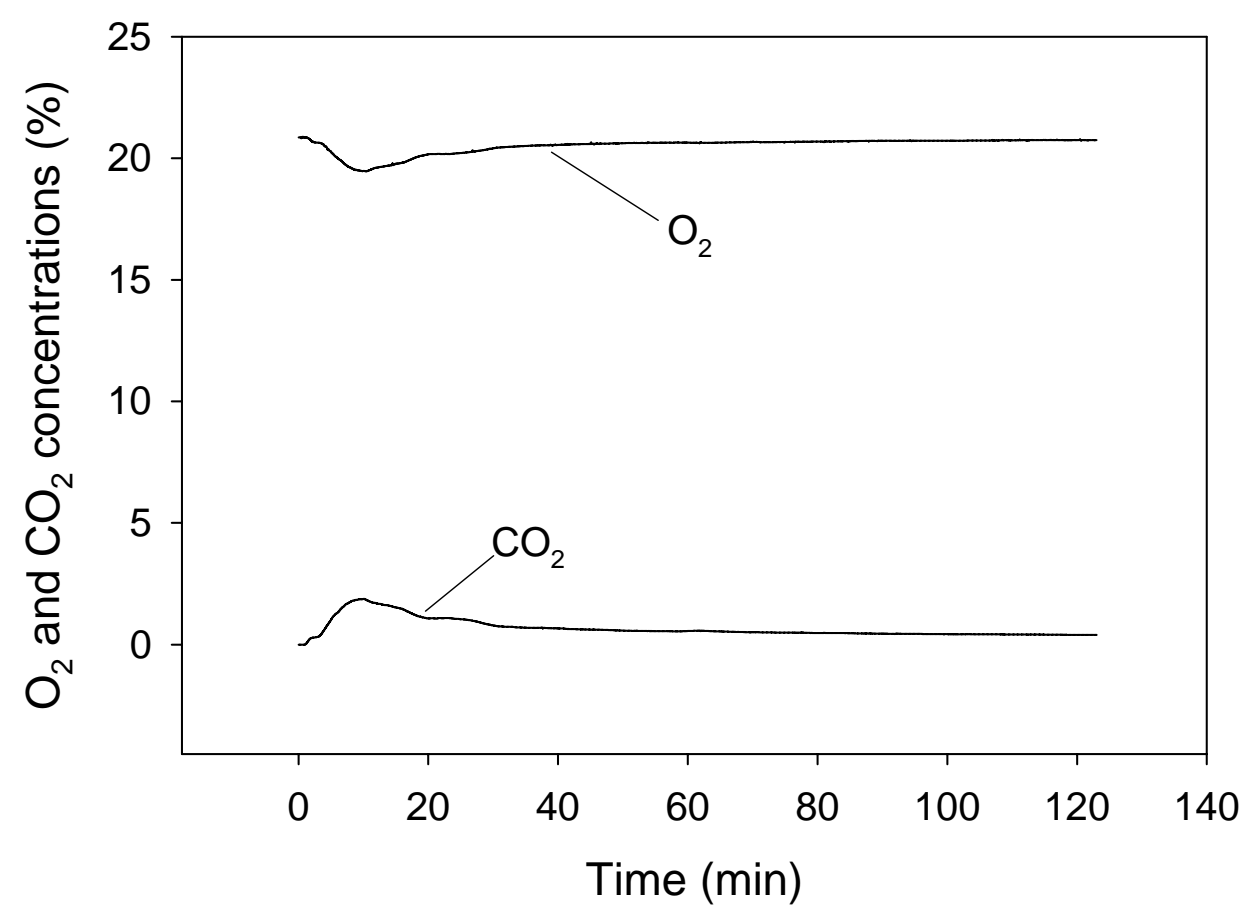

Figure S2: Representative profiles of oxygen and carbon dioxide concentrations. Presented profiles are for test 1120a. 

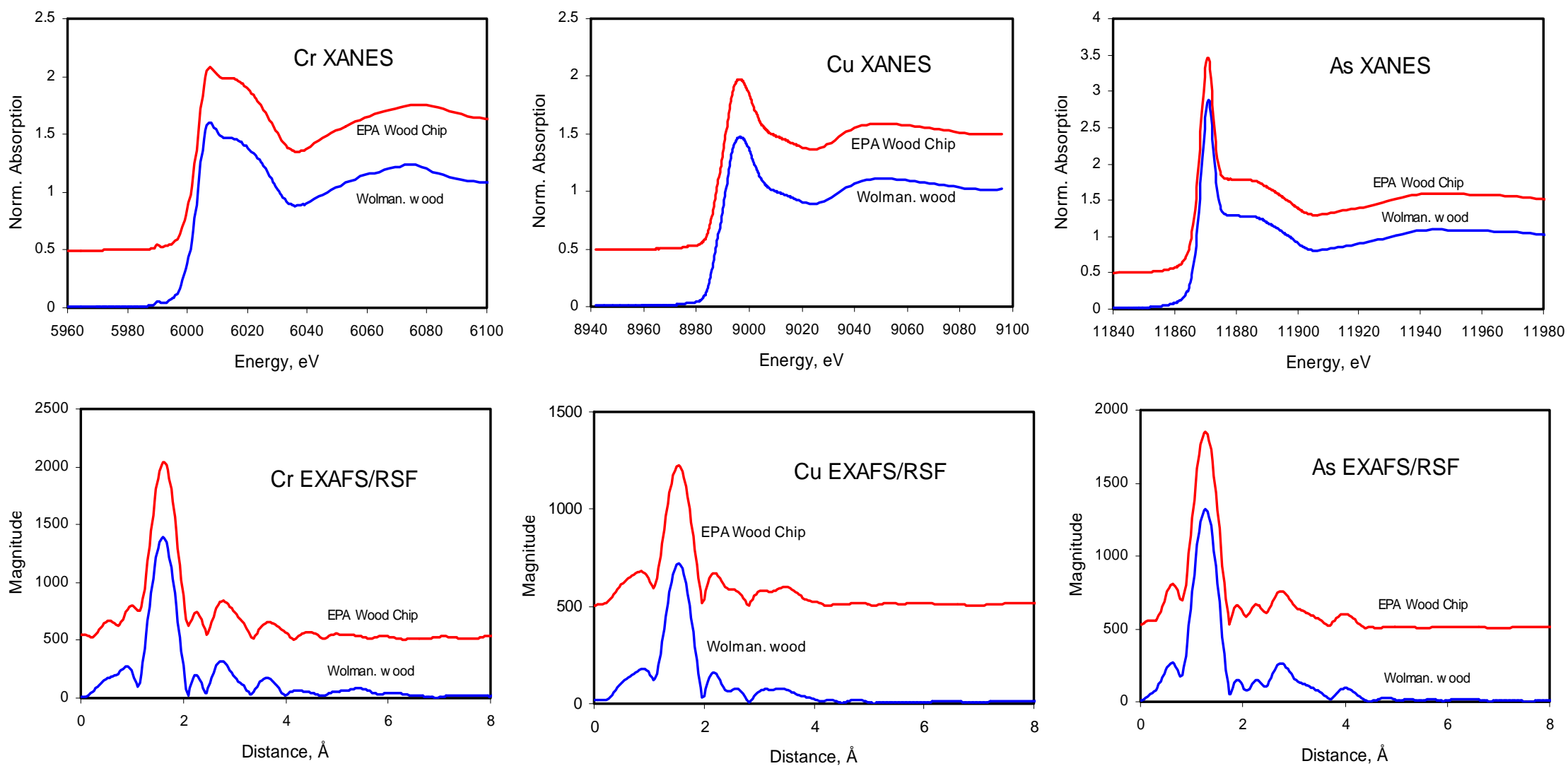

Figure S3: XAFS spectral data for $\mathrm{Cr}, \mathrm{Cu}$ and As in CCA treated wood samples. Both XANES and EXAFS/RSF data are shown for $\mathrm{Cr}, \mathrm{Cu}$ and As in two samples of CCA treated wood. The spectra shown in red derive from Type C CCA treated wood taken from a dismantled southern yellow pine deck after approximately 10 years of continuous outdoors exposure. The spectra shown in blue derive from a piece of CCA treated (Wolmanized ${ }^{\circledR} \# 2$ grade) dimensional lumber (2” x 4" x 8'). This block, which is at least 12 years removed from impregnation, has never been exposed to the elements. It was sawn to expose an interior surface for examination. The similarity of the spectra for all three elements in both wood samples is striking. The absence of a strong pre-edge peak in the Cr XANES spectra indicates that all (>97\%) of the $\mathrm{Cr}$ is $\mathrm{Cr}^{3+}$, whereas the shapes and positions of the prominent peaks in both the XANES and EXAFS/RSF are consistent with $\mathrm{Cr}^{3+}, \mathrm{Cu}^{2+}$ and $\mathrm{As}^{5+}$ oxidation states for the three elements. 

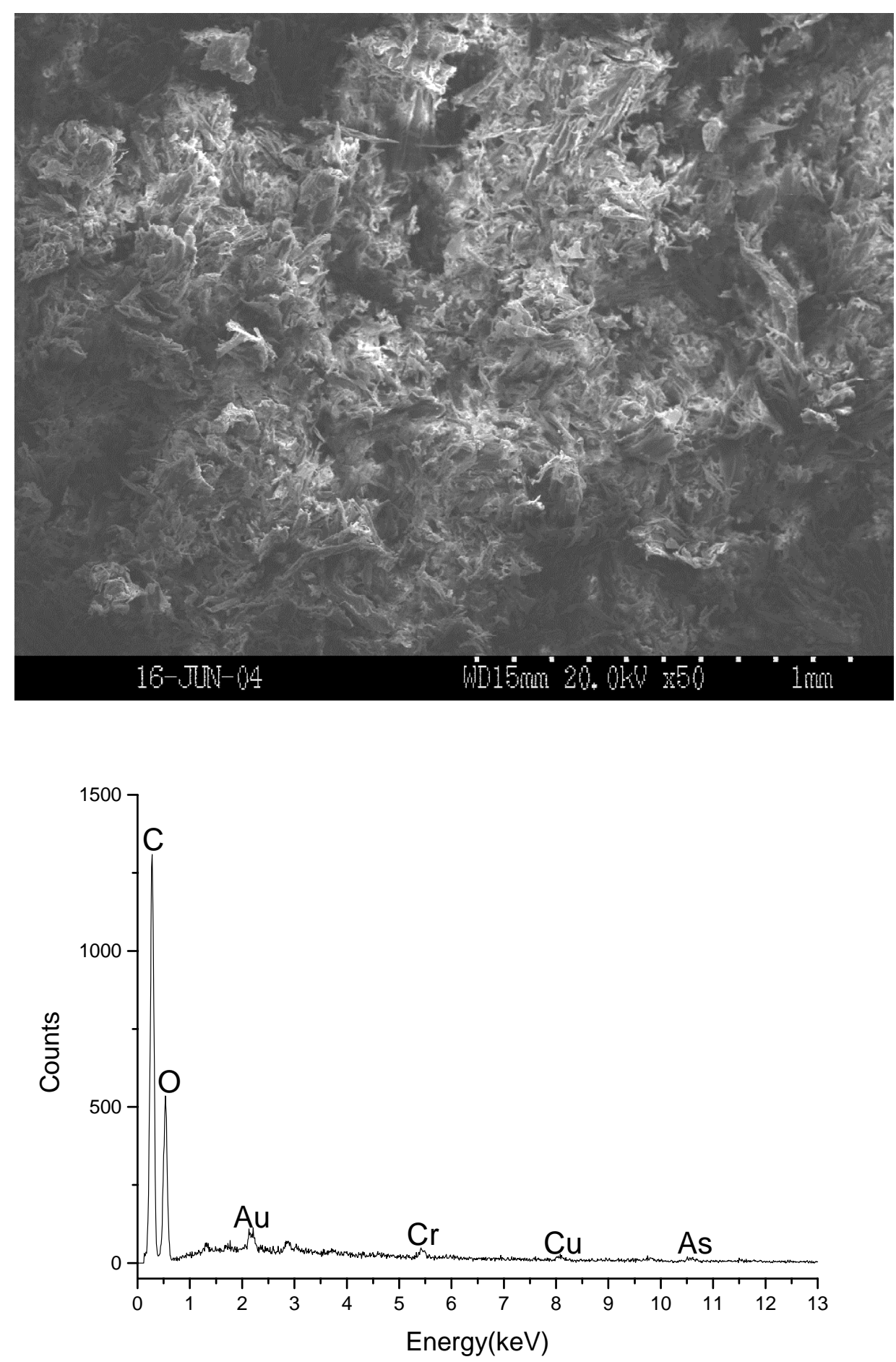

Figure S4: Typical SEM secondary electron image (top) of CCA treated wood sample from exposed decking and energy dispersive X-ray (EDX) spectrum of the corresponding area (bottom). The gold (Au) signal in the EDX spectrum arises from the conductive coating applied to the sample. Note the dominance of the peaks for carbon and oxygen, consistent with the fact that only about $1 \%$ of the mass of wood treated with $6.4 \mathrm{~kg} / \mathrm{m}^{3}\left(0.4 \mathrm{lb} / \mathrm{ft}^{3}\right)$ CCA preservative consists of $\mathrm{Cr}, \mathrm{Cu}$ and As. 

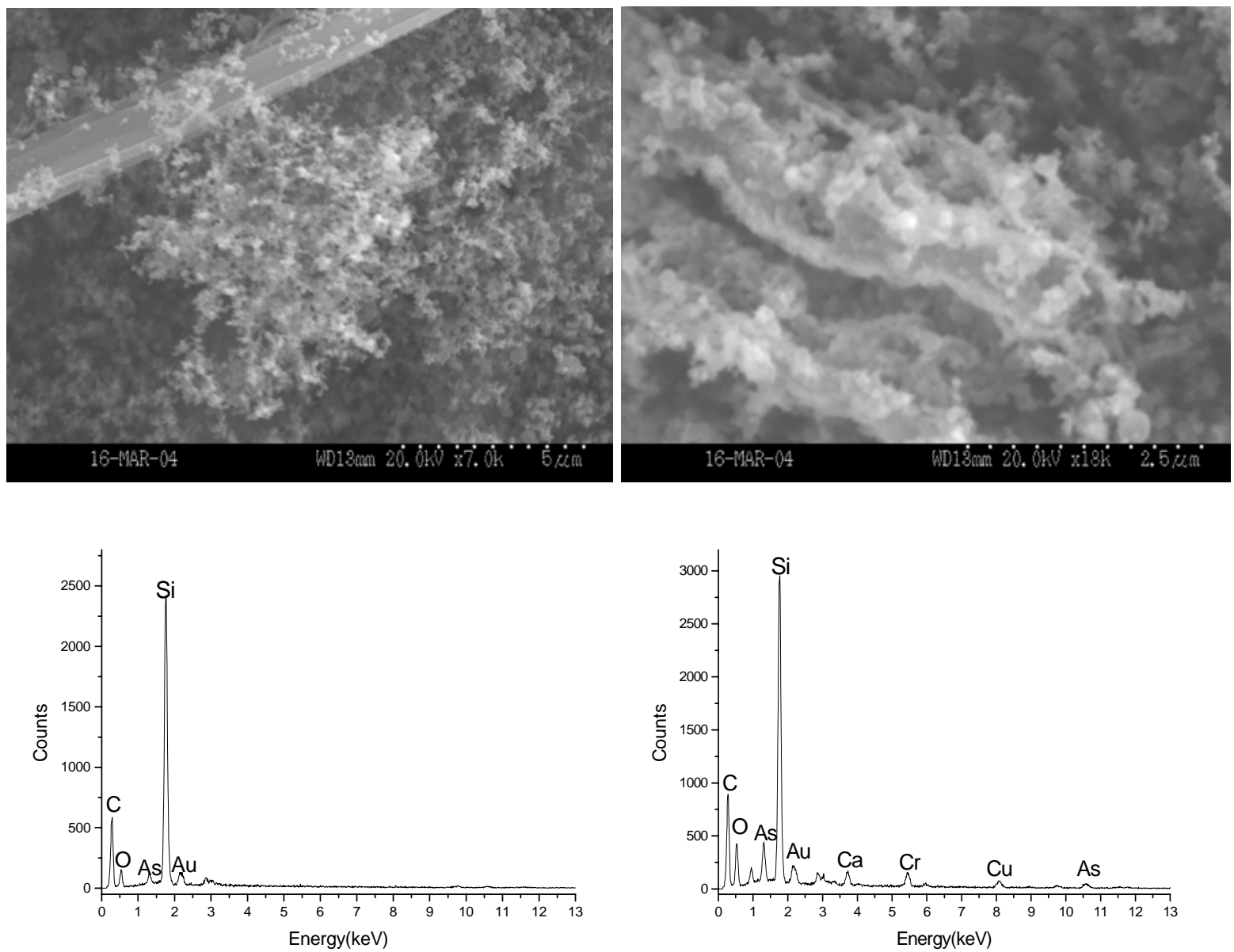

Figure S5: SEM images of soot aggregates in fly ash sample 1120a with the corresponding EDS spectra shown underneath. The strong Si signals are virtually entirely from the quartz filter substrate. For the left image, only weak arsenic signals were detected in the EDS spectrum; however, the right-hand image shows a tissue coke containing $\mathrm{Ca}$, $\mathrm{As}, \mathrm{Cu}$ and $\mathrm{Cr}$. 

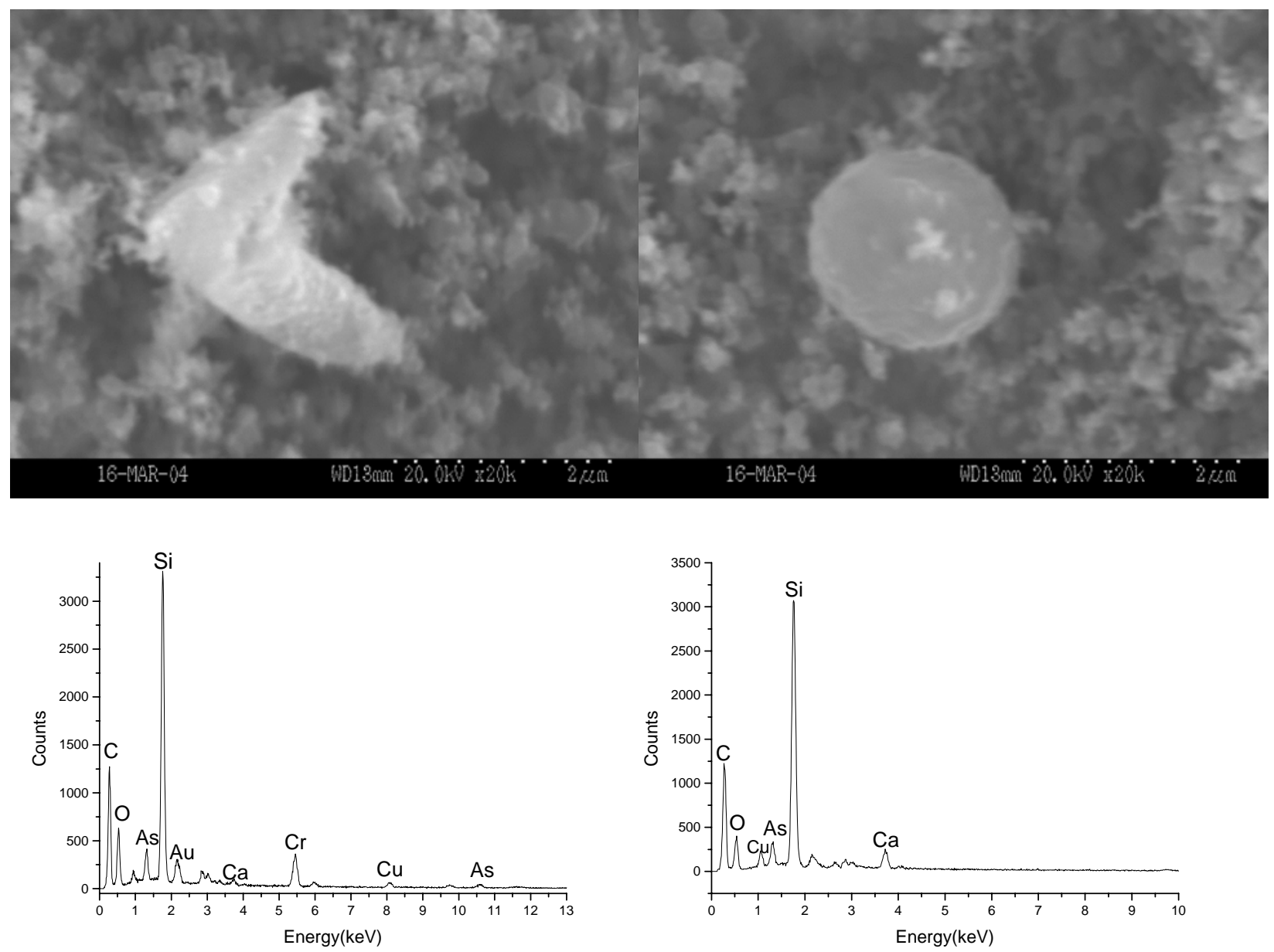

Figure S6: SEM images of two small individual particles in fly ash from CCA treated wood. Left: A particle enriched principally in Cr. Right: A spherical Ca-As oxide particle. 